\title{
Freire visto por Freire. La vigencia de la Pedagogía del oprimido
} Freire as seen by Freire. The validity of the Pedagogy of the oppressed

\section{Carlos Antonio Sánchez-Valverde Visus}

Universidad de Barcelona (UB), España

\section{Resumen}

Esta colaboración ofrece una revisión, realizada por el propio Freire y desde su propia palabra en 1994, de la vigencia de la Pedagogía del oprimido, en el marco de una conferenciacoloquio organizada por la ONG Infancia Viva y celebrada el 4 de julio de ese año en Barcelona (España).

Su importancia radica en el hecho de que Paulo Freire aprovechó para hacer un recorrido por su pensamiento, compartiendo cómo esa obra significa la madurez de su pensamiento, superando algunas carencias de obras anteriores (sobre todo de La Educación como práctica de la libertad) y poniendo en valor sus aportaciones ontológicas y epistemológicas. Y también, en cómo desde un diálogo abierto con el público, expresó sus opiniones sobre cuestiones de tipo más socio-político (la crisis de la izquierda, la situación en Brasil, etc.), como ser humano que lee el mundo.

La trascripción del portugués (o mejor dicho, del "portuñol", como él mismo nos aclaró), la adaptación y las anotaciones incorporan también algunos elementos de una entrevista que el autor pudo hacerle de manera informal en aquellas fechas. El resultado final del texto fue revisado por el mismo Freire.

Palabras clave: oprimidos, pedagogía, ontología, izquierda, Brasil, esperanza.

\section{Abstract}

This collaboration offers a review, made by Freire himself in 1994, of the validity of Pedagogy of the Oppressed, from his own word, within the framework of a conferencecolloquium organized by the NGO Infancia Viva (Alive Childhood) and celebrated on July 4th of that year in Barcelona (Spain).

Its importance lies in the fact that Paulo Freire took the opportunity to make a journey through his thought by sharing how this work means the maturity of his thought and overcoming some shortages found in previous works (above all in The Education as practice for freedom), and putting in value their ontological and epistemological contributions. And also, in how from an open dialogue with the public, he expressed his opinions on more socio-political issues (the crisis of the left, the situation in Brazil, etc.), as a human being who reads the world.

The transcription from Portuguese (or rather from "portuñol", as he himself made clear), the adaption and the notes incorporate also some elements of an interview that the author could have made to him in an informal way in those days. The final result of the text was reviewed by Freire himself.

Keywords: oppressed, pedagogy, ontology, left-wing, Brazil, hope. 


\section{Introducción}

Esta colaboración quiere rendir homenaje a este gran educadory pedagogo, poniendo de manifiesto la vigencia de sus propuestas pedagógicas y políticas, humanas en definitiva, desde una lectura crítica de su obra y trayectoria, hecha en primera persona por el mismo Paulo Freire.

Y a la vez, servir para un acto de revisitación. Revisitar a los clásicos para los educadores y educadoras es algo así como tomarse un momento de respiro, que nos ayuda a la revisión, la reflexión y a la interpelación crítica sobre nuestro quehacer.

El núcleo principal es la conferencia que Paulo Freire hizo el 4 de julio de 1994 en el Auditorio Sant Jaume de la Fundación La Caixa en Barcelona y que nunca ha tenido difusión en castellano (una primera versión fue publicada en catalán en un Boletín Interno de los Educadores y Educadoras Sociales de Cataluña en 2007).

La conferencia llevaba por título "La vigencia de la pedagogía del oprimido" y fue organizada por la ONG Infancia Viva. Freire había venido a Barcelona para participar en el Congreso Internacional "Nuevas perspectivas en la educación" que se celebró durante la primera semana del mes de julio de 1994, organizado por la Facultad de Pedagogía de la Universidad de Barcelona.

El desarrollo del acto fue muy dinámico, dada la posición, natural en él, que asumió Paulo Freire al afirmar que más que conferenciar, quería conversar y dialogar con el público, el cual le planteó algunos de los temas. Resulta muy interesante observar cómo a pesar de que casi hayan pasado casi 25 años de ese acto, las palabras de Paulo Freire mantienen todo su vigor y frescura y continúan aportándonos elementos para la reflexión y la acción.

La trascripción del portugués (o mejor dicho, del "portuñol", como él mismo nos aclaró), la adaptación y las anotaciones incorporan también algunos elementos de una entrevista que el autor pudo hacerle de manera informal en aquellas fechas. El resultado final del texto fue revisado por el mismo Freire.

Como curiosidades, decir dos cosas: una, que la única condición que Paulo Freire puso a la celebración y duración del acto estuvo marcada por su deseo de ver, indefectiblemente, la retransmisión del partido que la selección de Brasil jugaba ese día contra Estados Unidos (EE.UU.) a las 21,30h., dentro del campeonato del mundo de ese año celebrado en Estados Unidos (que se pudo ver en España por TVE1), lo que nos conecta con un Paulo Freire que lee el mundo y vive anclado 
en el mundo; y dos, respecto al artículo, compartir aquí que, originalmente en 1994, este artículo se concibió para ser publicado en una revista institucional de un organismo público catalán, que finalmente lo rechazó porque se consideraba que algunas de las afirmaciones de Paulo resultaban demasiado "comprometidas". Quizás ese rechazo pueda leerse como un homenaje más a Paulo Freire, al evidenciar el contenido político de la educación y la pedagogía.

Ortega y Gasset (1988) nos decía que la adquisición de la conciencia es el proceso en el que la vida como biología pasa a ser vivida como biografía. Paulo Freire nos ayuda a comprender mejor cómo se da este proceso.

\section{«Paulo Freire: La vigencia de la Pedagogía del oprimido}

Yo soy un viejo profesor brasileño que trabaja desde una perspectiva profundamente democrática y liberadora y que escribió un libro a principios de los 70 que se llamaba Pedagogía del oprimido, que tuvo mucha difusión. No es nada difícil para mi la tarea de intentar probar que lo que escribí hace 25 años es aún válido, aunque si la mayoría de ustedes acepta la propuesta, preferiría "conversar" con ustedes, "charlar" más que conferenciar. Así que ustedes podrían hacerme cualquier pregunta o sugerir algún tema, y si yo lo supiera contestar lo haría, y si no, se lo diría.

No tengo ninguna duda acerca de que todavía hay oprimidos. Hay mucha gente, sin embargo, que sí tiene esa duda, no sólo aquí, sino en todas partes... en el resto de Europa, los Estados Unidos, en América Latina... Leyendo algunos de los discursos fundamentales neoliberales, uno puede terminar haciéndose esta pregunta, dado el énfasis que este discurso pone en lo que "la historia ya ha muerto", que "las ideologías han terminado", que "la utopía ha desaparecido, ningún sueño es viable y ya no hay clases sociales y, que una vez terminadas las clases sociales, se ha acabado la lucha entre ellas". Entonces, ya no quedaría nada más de que hablar. No se debería hablar de ideología porque la ideología murió. Aunque cuando se hace esta afirmación se está haciendo ideología: sólo ideológicamente es posible matar la ideología. Es decir: si este discurso fuera verdad, no habría ya oprimidos. Pero yo no lo creo -nadie me

\footnotetext{
${ }^{1}$ Hemos de recordar que estas palabras fueron pronunciadas en 1994.
} 
Io ha demostrado hasta ahora- y por eso yo digo que todavía hay oprimidos y que la Pedagogía del oprimido es hoy más radicalmente fundamental que en la década de los setenta.

En el año 1992 publiqué un libro, traducido al castellano por la editorial mexicana Siglo XXI, y titulado Pedagogía de la esperanza: una revisión de la pedagogía del oprimido. La redacción de este trabajo la hice después de releer más de diez veces la Pedagogía del oprimido y, de hecho, quería ser una nueva introducción. Pero se convirtió en un libro diferente en sí mismo. Aunque yo creo que no está bien pedir a nadie que lea nada, creo que la Pedagogía de la esperanza tiene una lectura bonita, es más, no me da ninguna vergüenza decir que es un libro excelente (tengo horror de la falsa modestia, la cual, en la práctica, es mucho peor que la inmodestia...). En este libro he analizado lo que escribi, lo que dije, en la Pedagogía del oprimido. Y ahora me reafirmo en lo que dije entonces, y lo repito de manera aún más radical.

\section{Los orígenes: La educación como práctica de la libertad}

Pero, comencemos por el principio. La educación como práctica de la libertad fue el primer libro que escribi, para cuya redacción aproveché una tesis universitaria anterior de 1959 donde ya estaba la propuesta central de la Pedagogía del oprimido. Tan sólo faltaba superar algunas ingenuidades (no me cuesta nada reconocer mis limitaciones) cometidas en La educación como práctica de la libertad.

En este primer libro casi caí en una posición idealista-subjetivista que, obviamente, fue rechazada por los marxistas. Es interesante pensar sobre esta cuestión del rol de la conciencia o de la subjetividad dentro de la historia porque, por un lado, es cierto que la conciencia no es la constructora de la realidad y del mundo. Sin embargo, la conciencia y la subjetividad tampoco son un reflejo puro de la objetividad. La concepción de la conciencia como resultado automático de la realidad objetiva es una concepción de origen marxista que es equivocada, por su mecanicismo histórico. Yo nunca he aceptado la comprensión de la historia más que como un tiempo de posibilidad y no como un tiempo de determinismo. En el libro La educación como práctica de la libertad, sin embargo, corrí el riesgo de abrazar las posiciones idealistas. Por ejemplo, al presentar el famoso concepto de 'concientización', casi llegué a afirmar que bastaba 'concientizar' 
los hombres y las mujeres y que de esta manera, necesariamente, tendría lugar una especie de afección al proceso de transformación del mundo... Pero las cosas no son así.

La crítica a mis planteamientos ya la hice yo mismo hace veinte años. Puede que a veces no leamos todo lo que escriben algunos autores antes de hablar sobre ellos. Quisiera aprovechar este momento para hacer una reflexión académica, pero basada en la ética: creo que todo el mundo tiene el derecho de criticar a todos, pero hay que decir en qué se basa esta crítica. No es posible, por ejemplo, leer un libro de un autor que ha escrito quince y afirmar que con la crítica de un solo trabajo, se está analizando toda la obra de aquel autor. Creo que esto es inmoral. Yo mismo he sufrido mucho por culpa de este planteamiento. La educación como práctica de la libertad es mi primer libro y nadie puede decir al criticarlo que está criticando toda mi obra, mi pensamiento. Porque yo sigo vivo, mi cuerpo hace cosas, YO pienso, YO hablo, YO escribo... es decir, no me agoto en este primer trabajo. Si se me quiere criticar, es necesario haber estudiado toda mi obra.

A principios de los 70 publiqué un pequeño trabajo² que, de hecho, era una ponencia que se presentó en un encuentro que tuvimos en Ginebra Ivan Illich y yo. Ivan Illich presentó su concepto de "desescolarización" y yo trabajé sobre el concepto "concientización". En este texto hice mi autocrítica tratando de superar esta "caída" en el idealismo. La Pedagogía del oprimido supera de lejos esta limitación.

\section{La madurez: la Pedagogía del oprimido}

Así, mientras que en La Educación como práctica de la libertad no hice, ni siquiera una vez, la afirmación de que la educación, la práctica educativa, es sustantivamente una práctica política llena de ideología, el libro Pedagogía del oprimido está lleno de estas referencias... Recibí críticas en aquella época que decían que "mi concepto de oprimido era demasiado nebuloso y que le carecía un mayor acercamiento a la cuestión de las clases sociales". Sin embargo, de la lectura del libro se desprende otra cosa: hablo 36 veces de "clases sociales"; y

\footnotetext{
2 Los diálogos en Freire e Illich fueron frecuentes a inicios de los 70. En castellano se pueden encontrar en Freire, P.; Illich, I. (1973): Diálogo: desescolarización, estructuras, liberaciones, educación. Buenos Aires: Búsqueda-Celadec. Y en Freire, P.; Illich, I. (1975). La educación: autocrítica de Paulo Freire e Ivan Illich. Buenos Aires: Búsqueda
} 
en cuanto a la nebulosidad del concepto oprimido, he aprovechado mi última obra, Pedagogía de la esperanza, para afirmar que nunca nadie, sea un capitalista de Wall Street o un obrero de Barcelona, después de leer la Pedagogía del oprimido, puedan sufrir el riesgo de creer, el primero, que es un obrero y, el segundo, que es un industrial capitalista. A pesar de su contenido difuso, según algunos, cualquier hombre o mujer oprimidos que leyeran la Pedagogía del oprimido se identificarían como oprimidos. Y los potentados como a colonialistas imperialistas.

Recuerdo ahora un pequeño texto de una obrera "paulista" que se preguntaba: "¿quién es pueblo?". Y ella misma se contestaba: "pueblo es quien no se pregunta quién es pueblo". Encuentro esta respuesta de una gran sabiduría, no como las de otros sociólogos académicos que nunca han estado en la calle y hablan de lo que no conocen.

\section{Las nuevas propuestas: el rol del subjetivismo}

En la Pedagogía del oprimido hablo de todas estas críticas: la del subjetivismo, la del fracaso del mecanicismo... Por ejemplo: no tengo ninguna duda de que en los campos de la filosofía, de la ecología, de la política, etc. uno de los temas más fundamentales en el comienzo del próximo milenio volverá a ser nuevamente el rol de la subjetividad en la historia.

Sin lugar a dudas el pensamiento "moderno", desde los campos filosófico, epistemológico, desde la física moderna... ha aportado la presencia de la conciencia como "lo que hace el mundo", y este pensamiento no acepta que haya una nulidad en la subjetividad y en la producción del conocimiento. Creo que este tema volverá y que, cuando vuelva, se reproducirá la discusión en términos viejos, antiguos... y nuevamente perderán tanto la concepción subjetivista como la mecanicista. Para mí, la única salida a esta confrontación, la comprensión del rol de la subjetividad o de la conciencia, pasa por la comprensión de la naturaleza dialéctica de las relaciones entre objetividad y subjetividad. ¿Cómo se da la relación entre subjetividad y objetividad? Lo que constatamos es que las dos no se separan, no se dicotomizan: una no es la otra, pero ambas se implican entre ellas. En cuanto a este tema, resulta interesante pensar que cuando el científico habla de la objetividad de la ciencia, nos dice que tan sólo la objetividad de la ciencia explica la objetividad... pero, ¿dónde queda, pues, la subjetividad del científico? ¡Como si no existiera! 
La objetividad no existiría sin la subjetividad y viceversa: nosotros inventamos esta conciencia del mundo que provoca la conciencia de mí mismo. No es la conciencia de uno mismo la que nos da la conciencia del mundo. Es la conciencia del "no yo" la que me hace consciente de mí mismo. Dialécticamente. Así, no tengo ninguna duda de que, por ejemplo, desde el punto de vista político, todas las implicaciones que se dan en la lucha política en relación con la subjetividad y con la objetividad deberán ser rehechas. Ya no es posible por más tiempo una posición de transformación del mundo, basada en una concepción mecanicista de la historia y de la conciencia.

Sin embargo, a pesar de todas estas afirmaciones, no hago renuncia de mi libro La educación como práctica de la libertad, del que os tengo que decir que todavía hoy se hacen reediciones. Un poco también para que los lectores puedan tener una idea más amplia de mi proceso, de mis momentos indecisos, y para que descubran en otros lugares mis superaciones.

\section{El rol de la izquierda después de la caída del muro de Berlín}

Con la "caída del muro de Berlín" imagino que en todas partes ha pasado lo mismo que pasó en Brasil. Es decir, que las izquierdas, como herederas del pensamiento "moderno" (Marx fue un pensador moderno), basaban sus fundamentos en el carácter científico de su discurso. Y la cuestión era cómo pasar a la postmodernidad sin caer en la negación de la modernidad y de sus hallazgos, sin caer en errores "por el otro lado". El pensamiento modernoracional significó la absolutización de la certeza: "yo estoy absolutamente cierto de mi certeza". Y los marxistas también estaban ciertos de sus certezas. Y pasó que estas certezas desaparecieron. Por diferentes razones, incluso porque Marx había acertado en su análisis y posibilitó la anticipación del contrario en sus proyectos anulando los mismos.

La cuestión ahora, para mí, pasa más por "no estar demasiado ciertos de las certezas". Y es en la medida en que yo dejo de estar totalmente cierto de mis certezas, cuando comienzo a tener certezas. Estoy creando certezas al negar la incertidumbre. Esto es una posición dialéctica, no mecánica.

Cuando cayó toda esa construcción del socialismo real, hubo una sensación general similar a un "iDios nos guarde!". Mucha gente de izquierdas empezó a creerse los discursos neoliberales pasándose al lado del pragmatismo. Yo tuve 
que escuchar de mi obra cosas como "el tiempo de la pedagogía de Freire ha terminado". Y aún más allá, decian "hoy necesitamos una pedagogía pragmática". Y no en el sentido puro y llano del pragmatismo, sino en el sentido de querer decir: "la enseñanza de las cosas que son inmediatamente necesarias para la supervivencia". „Como si lo único importante fuera que los hombres y las mujeres de hoy sólo aprendieran "habilidades" concretas! Y sólo a los representantes de las élites les quedaría la posibilidad de un camino más largo hacia la ciencia y la tecnología pero desde una postura en la que no habría que hacer ninguna pregunta en relación con los objetivos de la práctica humana. Lo ideal para esta pedagogía pragmática sería, por ejemplo, capacitar a un tornero para hacer su trabajo (hacer tornillos). Pero sin decirle nada sobre dónde vive y con quién y contra quién vive y trabaja. Esto, nos dicen, ya no es educación necesaria. Esto es subversión.

\section{La verdadera naturaleza ontológica del hombre}

Pues yo creo que es precisamente esto lo que es realmente la educación. No hacerlo significa castrar la capacidad de invención y de conocimiento que los hombres y las mujeres han construido históricamente. Lo que nos diferencia a nosotros, de un perro, como ejemplo, es que nosotros hemos sido capaces de crear la capacidad de curiosidad que llega después a convertirse en una categoría epistemológica. En un primer momento, tanto el hombre como los animales son curiosos, pero estos no traspasan los límites de su especie. Nosotros, los humanos, sobrepasamos a la especie. Yo no puedo ser entendido en mi actuar solamente desde lo que es común a la especie humana. Nosotros somos más que la especie. En el mismo momento en que nosotros diferenciamos la comprensión de nuestro comportamiento de la del comportamiento general de la especie, hicimos una cosa maravillosa, con la que hemos contribuido a la cultura, a la historia y al saber. Y esta fue exactamente la de crear la posibilidad de ser diferentes (incluso hemos llegado a nacer mucho más diferenciados que los de otras especies). Después, los hombres crearon la utopía de la igualdad. Si al nacer fuéramos iguales, si fuéramos biológicamente iguales, no habría manera de crear el concepto de igualdad. La hemos creado, precisamente, porque no somos iguales, porque no hay igualdad. Porque necesitamos serlo.

Dicho de otro modo, en vez de experimentar este tipo de curiosidad, que yo digo "espontánea", el hombre y la mujer inventaron la curiosidad "epistemológica", una curiosidad ordenada, metódicamente organizada, que está en la base de 
lo que posibilitó la ciencia. Y eso es una invención nuestra. Esta curiosidad que se transformó en una cualidad de la propia naturaleza, del "ser del ser": es decir, ser curioso epistemológicamente, hoy forma parte de la naturaleza del ser humano porque fue una creación histórica. Y yo no tengo ningún miedo en decir que "la curiosidad epistemológica es ontológica", que forma parte de nuestra naturaleza. Por ello, cualquier intento de castración de la ontología del ser es una violencia.

Volviendo al principio: el pragmatismo neoliberal es profundamente criminal. Porque reducir la práctica educativa a un puro saber periférico del ser de las cosas es un absurdo. Yo no estoy en el mundo para aprender sólo a sentarme en una silla, sino también para aprender a hacer la silla y para saber a quién sirvo haciendo la silla. Para mí esta posición es radical y no me sabría mal gritar, aunque con mucha tristeza, "yo soy ser humano", si todo el mundo encontrara que es el liberalismo el que está acertado y que la educación debe ser simplemente periférica a mi ser. No, o ella es algo más que penetra y sale de mi ser, o no sirve. De ahí surge mi radicalidad... Perdonadme porque creo que estoy dedicando demasiado tiempo a los neoliberales, pero es como una especie de rabia individual, de "grito" en defensa de mis posiciones... En eso, soy un poco español.

Les explicaré un dicho de mi país: en Brasil se dice que cuando un español llega a un país, pregunta: "¿dónde está el gobierno?" Y que cuando se le contesta, responde: "ipues yo estoy aquí, del otro lado, contra el gobierno!". Dejadme ser un español radical en mi derecho a criticar, porque aunque tengo un horror terrible a parecer manipulador, a parecer no respetuoso con los demás, prefiero la adhesión de las personas y no el miedo...

Bueno, para acabar con este tema tan sólo diré que había muchos que se llamaban de la izquierda y que me trataban de "pedagogo burgués ambiguo", pero yo me considero todavía un radical. Hoy La pedagogía del oprimido es más radical aún, que en los años 70, cuando salió. Más radical y más oportuna. Y fue por eso que escribí la otra, La pedagogía de la esperanza, como una relectura. Y la escribi con rabia. Para mi es muy difícil diferenciar la rabia del amor. Lo que yo hago es disociar el amor del odio. No soy capaz de odiar, pero de tener rabia, si que soy capaz. De hecho, las grandes cosas que he hecho en la vida, las he hecho en momentos de rabia. Bueno, este libro lo escribi así, icon rabia! 
Y me pone muy triste ver como hoy mucha gente que tiene el coraje de decir que es de izquierdas y que se queda en el pragmatismo...

\section{Ser de izquierdas hoy}

Yo, hoy, lo digo con más fuerza que antes: isoy de izquierdas! Y no soy sectario: entiendo que no se puede ser de izquierdas e intolerante, es como una especie de derroche... No hay que tener miedo de llamarse radical y de izquierdas, porque sigue habiendo izquierdas y derechas. ¿Cómo podría desaparecer esta división de la noche a la mañana? ¿Puede ser que el discurso neoliberal sea más que la historia y sea capaz de cambiar la historia? No, es también fruto de la historia. Entonces, como hombre de izquierdas, creo que lo que pasó con el socialismo real es que el marco en el que nació y creció la experiencia socialista era un marco sustancialmente autoritario. Esto es para mí lo que deshizo el sueño socialista. Por el contrario, el marco donde nació, floreció y creció el capitalismo es un marco democrático. La izquierda, equivocadamente, decía que era una democracia "burguesa" y que, por tanto, teníamos que estar en contra. Y esta posición antagonista imposibilitó, inviabilizó, cualquier tipo de relación entre socialismo y democracia. No, la burguesía no tiene el derecho exclusivo sobre la democracia. Es más, sin miedo a equivocarme o a parecer metafísico, hoy diría que la democracia forma parte de nuestra ontología: es desde la democracia desde donde podemos plantearnos la vocación humana de ser más, evitando la deshumanización, la negación del ser más.

No debemos tener miedo a responder a la pregunta: ¿Qué pasó? ¿Por qué cayó el muro? Recuerdo que un día, en los Estados Unidos, me preguntaron: "¿Qué piensa usted de toda esta derrota que está sucediendo en la historia?" Y yo dije: "Desde mi punto de vista, quizá no ahora, pero seguro que muy pronto, conseguiremos comprender mejor todo esto, percibiendo, por último, que 10 que ha pasado ha sido una especie de oda a la libertad. Creo que hubo un momento en que diferentes pueblos, clases quizás, se agotaron con la experiencia impositiva del socialismo, como diciendo, 'el socialismo está bien, pero que no me obliguen a hacer esto o aquello'. Yo defiendo una perspectiva democrática en la que 'yo decido', frente a los sistemas en los que otros deciden por mí. 


\section{Paulo Freire ¿pensador marxista?}

A mí me han identificado muchas veces como pensador marxista y, honradamente, debo decir que no puedo considerarme marxista, porque los marxistas no pueden aceptar ningún "apriorismo" de la historia. Los marxistas sólo pueden funcionar al nivel de la intimidad de la historia. Y no me puedo considerar marxista porque creo en Dios, aunque, como mucha gente, a veces tengo dudas. Y no renunciaré a esta creencia para ser agradable ni a Marx ni a nadie. Es más, no veo ningún obstáculo en la creencia en Dios. Al contrario, soy profundamente radical precisamente como consecuencia de mis creencias. No puedo entender cómo personas que se consideran creyentes pueden discriminar a otras personas. No entiendo como alguien puede decir "yo creo en Dios, pero estos negros deberían estar en África". Esto es absurdo y una brutal incoherencia. O, como se puede creer en Dios y ser "machista" (o como se puede ser "marxista" y "machista"). Pero hay miles de seres contradictorios...

Entonces, es mi rigor, sin caer en el positivismo (me declaro dialéctico), el que me hace decir: "no soy marxista porque yo heriría Marx". Aunque acepto muchos de los análisis marxistas sin ningún tipo de duda, y los acepto como totalmente vigentes. No están pasados de moda. Marx nos pidió que hicieran algo que no hemos hecho: ir más allá de él mismo. Hacer como él cuando les decía en vida a un grupo de seguidores franceses: "yo no soy marxista". Ahora, renunciar a él, renunciar a esta posición acertada, humanista... y decir que el capitalismo es algo bueno... esa postura no la esperen nunca de mí.

Si ustedes creen que estoy equivocado, me lo pueden decir sin miedo. Marcharé de esta sala sin enfadarme.

Bueno, lo que estoy intentando hacer en el tiempo que me queda de vida (espero vivir un poquito más, porque me gusta vivir...), y lo estoy haciendo escribiendo mucho, es exactamente continuar en esta lucha, continuar lleno de vida y de fuerza aunque pierda las fuerzas, para gritar las cosas en que creo, para poder trabajar y, sobre todo, lo hago esperanzado. Creo también que la esperanza es una condición necesaria de la existencia humana; sin esperanza no creo que se dé la posibilidad de ser. 


\section{La situación política en Brasil}

Bueno, una cosa rápida antes de irnos. Creo que tengo el deber de hablar dos minutos sobre la política.

Soy un hombre político. Y esto es muy interesante. Soy político porque soy pedagogo. Hay pedagogos que son pedagogos porque son políticos. Yo soy lo contrario. No me mueve ningún interés para ser diputado, senador... Mi sueño permanente es ser profesor (por eso sigo dando clases, a pesar de mis 72 años).

La situación actual de Brasil, sin embargo, es una situación política en la que puede terminar ganando el intento de mejorar este absurdo brasileño de tener 33 millones de brasileñas y brasileños muriendo de hambre. Es una vergüenza en una sociedad considerada la octava o novena economía del mundo. Algo debe de estar equivocado en esta economía que mantiene más de 33 millones de personas muriendo de hambre y a otros 33 millones más en situación de pobreza extrema. Es decir, que la economía brasileña está funcionando bien para el resto de la población, para los 50 millones restantes.

Yo mismo, que soy un profesor universitario, formo parte del primer mundo, del mundo feliz, en Brasil. Las personas que se mueven a nuestro alrededor y que están ganando entre 300 y 350 dólares al mes son las que están en el mínimo de la economía sistémica. Y los que viven en la economía invisible, ¿cuánto ganan? Es absurdo que la normalización sistémica se encuentre en esta cifra.

Y tenemos, además, 8 millones de niños y niñas sin escolarizar... Vivimos en una sociedad que cuenta los felices... Esto debe cambiar. Y Lula33, para mí, es una utopía realizable. Las encuestas actuales dicen que si las elecciones se hicieran ahora, él resultaría elegido presidente en la primera vuelta. Esperamos que esto continúe así hasta el 3 de octubre, porque si se ha de celebrar una segunda vuelta, toda la derecha se unificará y será más difícil.

Si me preguntaran si Lula es la solución a todos los problemas brasileños, respondería: "No!". No espero milagros. Pienso en clave de historia, no en metahistoria. Los milagros se hacen en la metahistoria o por Dios en la historia, pero

\footnotetext{
${ }^{3}$ En el momento en que se realizó esta conferencia aún no había comenzado la campaña electoral para la presidencia de Brasil. Las elecciones se celebraron en octubre de 1994 y resultó elegido el candidato del Partido Socialdemócrata, Cardoso. Lula, el candidato del Partido de los Trabajadores, como bien había previsto Paulo, quedó en segunda posición en la segunda vuelta.
} 
los hombres no hacen milagros. No hay hombre, por más bueno que sea, que sea capaz de resolver los problemas de Brasil en tan sólo cuatro años. Entonces, podrian preguntarme: ¿qué esperas, pues, Paulo? Bueno, pues espero que se introduzcan algunas soluciones a algunos problemas y que esta introducción guste al pueblo y pueda continuar con una labor más profunda de cambio de la sociedad brasileña. No soy pesimista, soy un optimista vital y espero que la próxima vez que vuelva aquí pueda informarles de las soluciones que se hayan podido aportar por todos nosotros, no sólo por Lula.

Gracias y hasta dentro de un rato!»

\section{BIBLIOGRAFÍA}

Ortega y Gasset, J. (1988). El tema de nuestro tiempo. Madrid: Espasa-Calpe. (editado originalmente en 1923). 